\title{
A formação pedagógica de docentes bacharéis na educação superior: construindo o Estado da Questão
}

\author{
Conceição de Maria Pinheiro Barros \\ Ana Maria lorio Dias \\ Universidade Federal do Ceará
}

\section{Resumo}

Este estudo tem como objetivo analisar contribuições de pesquisas brasileiras sobre formação pedagógica do docente bacharel. Fundamenta-se em autores como Cunha (2004), Masetto (1 998) e Tardif (2002). Como metodologia, utilizou-se pesquisa do tipo Estado da Questão (MARCONI; LAKATOS, 2001 e SILVEIRA; NÓBREGA-THERRIEN, 201 1), com coleta de dados realizada no Banco de Teses da Coordenação de Aperfeiçoamento de Pessoal de Nível Superior, na Biblioteca Digital Brasileira de Dissertações e Teses, em periódicos e anais de eventos científicos. Concluiu-se que esse profissional deve possuir 42 conhecimentos pedagógicos e que é necessário o aprofundamento de estudos em busca de soluções para essa situação.

Palavras-chave: Formação de professores. Docente bacharel. Educação superior.

\section{The pedagogical formation of the bachelors teachers of higher educa- tion: building the State of the Question}

\section{Abstract}

This study aims to analyze contributions of Brazilian researches on pedagogical formation of bachelor teacher. It is based on authors as Cunha (2004), Masetto (1998) and Tardif (2002). The methodology we employed was a survey like the type of State of the Question (MARCONI; LAKATOS, 2001 and SILVEIRA; NÓBREGA-THERRIEN, 2011 1), with data collection performed in Theses Bank of Personnel Improvement Coordination of Higher Education, in the Brazilian Digital Library of Dissertations and Theses, in journals and annals of scientific events. It was concluded that this professional must have pedagogical knowledge and that is necessary the deepening of the studies to search solutions to this situation.

Keywords: Teachers formation. Bachelor docent. Higher education. 


\section{La formación pedagógica de los profesores licenciados en la educa- ción superior: construyendo el Estado de la cuestión}

\section{Resumen}

Este estudio analiza contribuciones de investigaciones brasileñas acerca de formación pedagógica de profesores licenciados. Se basa en autores como Cunha (2004), Masetto (1998) y Tardif (2002). La metodología utilizada fue un estudio del tipo Estado de la Questión (MARCONI; LAKATOS, 2001 y SILVEIRA; NÓBREGA-THERRIEN, 2011 1), con recogida de datos realizada en Banco de Teses da Coordenação de Aperfeiçoamento de Pessoal de Nível Superior, en Biblioteca Digital Brasileira de Dissertações e Teses, en periódicos y anales de eventos científicos. Se concluyó que este profesional debe tener conocimiento pedagógico y que es necesaria una profundización de estudios en busca de soluciones para esta situación.

Palabras clave: Formación de profesores. Docente bachiller. La educación superior.

\section{O docente bacharel na educação superior: e a formação pedagógica?}

A formação e os saberes de professores para atuação na educação superior têm sido preocupação de estudiosos da área nas últimas décadas. Neste texto, destacamos autores como Cunha (2004), Masetto (1 998), Tardif (2002). O debate acerca dessa temática centra-se na ausência de preparação pedagógica para a ałuação na educação superior, o que, consequentemente, se reflete nas práticas pedagógicas de profissionais com formação na modalidade bacharelado em sala de aula. A Lei de Diretrizes e Bases da Educação Nacional (LDB), Lei nº 9.394, de 20 de dezembro de 1996, em seu art. 66, estabelece que "[...] a preparação para o exercício do magistério superior far-se-á em nível de pós-graduação, prioritariamente em programas de mestrado e doutorado" (BRASIL, 1996, p. 22). Entendemos que o termo "preparação" seja insuficiente para traduzir a relevância da formação pedagógica, que consideramos imprescindível para o exercício da profissão docente; daí a necessidade urgente de se rever/reformular este artigo.

Vasconcelos (2000) afirma que a universidade' é (deve ser?) responsável pela formação do seu quadro docente. Embora considere a importância 
A formação pedagógica de docentes bacharéis na educação superior: construindo o Estado da Questão

dos conhecimentos adquiridos nos programas de pós-graduação, para o autor, a titulação não indica que o professor esteja preparado para o desempenho do seu papel em sala de aula. Cunha (2004, p. 526), ao discorrer sobre a constituição da docência na educação superior, alerta que "[...] diferentemente dos outros graus de ensino, esse professor se constituiu, historicamente, tendo como base a profissão paralela que exerce ou exercia no mundo do trabalho".

Com base nessas reflexões, consideramos a necessidade de estudos críticos sobre essa temática, visando obter subsídios que contribuam para a busca de caminhos formativos para a docência, adequada à realidade contemporânea da educação superior. Nessa perspectiva, indagamos: o que dizem as pesquisas brasileiras sobre a formação pedagógica do docente da/na educação superior que é bacharel - e que, portanto, não teve essa formação pedagógica, sequer para a Educação Básica, como a ofertada em cursos de Licenciatura? Assim, este estudo tem como objetivo analisar as contribuições de pesquisas brasileiras sobre a formação pedagógica do docente bacharel. Mais especificamente, busca apresentar a construção do Estado da Questão (EQ) acerca do tema "formação pedagógica de professores bacharéis da educação superior". Conforme Nóbrega-Therrien e Therrien:

A finalidade do EQ é a de levar o pesquisador a registrar, com suporte em um rigoroso levantamento bibliográfico, como se encontra o tema ou o objeto de sua investigação no estado atual da ciência ao seu alcance (NÓBREGA-THERRIEN E THERRIEN, 2010, p. 34).

Estado da Questão foi desenvolvido com o intuito de conhecer os enfoques de pesquisas de dissertações e teses brasileiras, bem como dos artigos científicos publicados em periódicos e eventos científicos, possibilitando uma visão acerca do cenário dessa área e de contribuições que a pesquisa proposta poderá oferecer para as discussões sobre o tema. De acordo com Silveira e Nóbrega-Therrien (201 1, p. 220): "[...] o pesquisador, disposto a realizar o Estado da Questão [...], poderá exercer seu levantamento mediante vários meios possíveis de busca". Nessa perspectiva, foi feita uma coleta de informações por meio de pesquisas em dois bancos de dados: Banco de Teses da Coordenação de Aperfeiçoamento de Pessoal de Nível Superior (CAPES) e Biblioteca Digital Brasileira de Dissertações e Teses (BDTD), no período de 
março a abril de 2014. Além disso, foi feita uma busca em artigos em revistas e eventos científicos, em maio de 2014.

A realização desta pesquisa parte do pressuposto de que a Educação tem um papel primordial para a sociedade por ser poderoso instrumento de transformação e, para que isso seja possível, a formação para a docência deve ser considerada como o principal fundamento para a atuação do professor bacharel na educação superior. Sobre o papel social da educação, Durkheim (2007, p. 53) pondera que "[...] educação é a ação exercida pelas gerações adultas sobre aquelas que ainda não estão maduras para a vida social". Por meio da educação, o homem pode transformar a realidade na qual está inserido, como se constata em Freire (2009, p. 16), que considera que "[...] a educação não é um processo de adaptação do indivíduo à sociedade. 0 homem deve transformar a realidade". Nessa perspectiva, emerge o papel social da Instituição de Educação Superior (IES) e, nela, do professor desse nível de ensino, contribuindo para as mudanças.

Segundo Masetto (1998), até a década de 1970 as IES brasileiras selecionavam seu corpo docente entre os profissionais renomados em determinada área do conhecimento; exigia-se profundo conhecimento das disciplinas a serem lecionadas e competência na prática da profissão. Cunha (2004, p. 526, grifos da autora ) afirma que a ideia de que "[...] quem sabe fazer sabe ensinar deu sustentação à lógica do recrutamento dos docentes".

Entendemos que, além de competência técnica, dos conhecimentos específicos e da experiência na profissão, a prática de ensino na educação superior requer o desenvolvimento de saberes pedagógicos. Na compreensão de Gil (2009), o docente que atua na educação superior necessita, além de sólidos conhecimentos específicos na área em que leciona, de habilidades pedagógicas que tornem o processo de aprendizagem eficaz. Tal percepção denota que a atuação na docência na educação superior exige a construção de uma diversidade de saberes. Ao conceituar saberes da docência, Tardif (2002, p. 36) destaca "[...] como um saber plural, formado pelo almágama, mais ou menos coerente, de saberes oriundos da formação profissional e de saberes disciplinares, curriculares e experienciais [...]"; os saberes da experiência são os conhecimentos advindos da prática profissional. Defendemos que a atuação de docentes bacharéis necessita de conhecimentos que ultrapassam a formação específica e a prática profissional. 
A formação pedagógica de docentes bacharéis na educação superior: construindo o Estado da Questão

A lacuna relativa aos conhecimentos pedagógicos, existente na formação recebida pelo professor bacharel, tem como consequência constantes desafios enfrentados em sua prática de ensino. Tal situação induz, constantemente, a indagações a respeito do seu papel e do futuro da sua profissão. As questões ora suscitadas foram o ponto de partida para a busca de pesquisas acerca do tema, levando à realização da construção do Estado da Questão. Os caminhos percorridos, nessa investigação, são apresentados a seguir.

\section{O Estado da questão: metodologia da investigação e o percurso para o mapeamento das informações}

Uma pesquisa bibliográfica trata do mapeamento da produção "[...] já publicada em forma de livros, revistas, publicações avulsas em imprensa escrita [...], documentos eletrônicos [...]", uma vez que a finalidade é "colocar o pesquisador em contato direto com tudo aquilo que foi escrito sobre determinado assunto [...]" (MARCONI; LAKATOS, 200 1 , p. 43-44), com o objetivo de permitir ao cientista análises com objetivos os mais diversos. Para Eco (2008, p. 42), "[...] organizar uma bibliografia significa buscar aquilo cuja existência ainda se ignora". Dessa forma, quanto aos procedimentos técnicos, foi realizado um levantamento bibliográfico a partir da consulta a livros, artigos e outras publicações sobre o tema proposto, seguido da construção do Estado da Questão. Para a elaboração do Estado da Questão, foram selecionados quarenta e sete (47) trabalhos, distribuídos da seguinte forma: quatorze (14) dissertações, nove (9) teses, oito (8) artigos publicados em revistas científicas e dezesseis (16) trabalhos publicados em anais de eventos.

O percurso para o mapeamento das informações foi feito, inicialmente, com o intuito de localizar dissertações e teses nacionais que abordassem a formação pedagógica e a atuação do docente bacharel, a partir dos seguintes descritores: docente bacharel, saberes pedagógicos de bacharéis, saberes pedagógicos para educação superior, docência universitária, formação inicial e formação continuada. Nessa fase, foram identificados cem (100) trabaIhos, distribuídos da seguinte forma: setenta e oito (78) dissertações e vinte e duas (22) teses. Após a leitura dos resumos, foram eleitas vinte e três (23) pesquisas para a construção do Estado da Questão, defendidas no período de 2005 a 2013 . A escolha dessas pesquisas foi feita por considerarmos as suas 
contribuições para o tema proposto. A Tabela 1 apresenta uma síntese quantitativa dos trabalhos identificados e selecionados de acordo com as fontes de coleta de dados.

Tabela 1

Síntese quantitativa dos trabalhos identificados e selecionados a partir das fontes de dados

\begin{tabular}{|c|c|c|c|c|}
\hline Descritores & Fonte & $\begin{array}{l}\text { Total de } \\
\text { registros }\end{array}$ & $\begin{array}{c}\text { Total de } \\
\text { trabalhos } \\
\text { relacionados } \\
\text { ao tema }\end{array}$ & $\begin{array}{c}\text { Total de } \\
\text { trabalhos } \\
\text { selecionados }\end{array}$ \\
\hline \multirow{2}{*}{$\begin{array}{l}\text { Docente } \\
\text { bacharel }\end{array}$} & CAPES & 13 & \multirow[t]{2}{*}{31} & \multirow[t]{2}{*}{16} \\
\hline & BDTD & 37 & & \\
\hline \multirow{2}{*}{$\begin{array}{l}\text { Saberes pe- } \\
\text { dagógicos de } \\
\text { bacharéis }\end{array}$} & CAPES & 0 & \multirow[t]{2}{*}{8} & \multirow[t]{2}{*}{2} \\
\hline & BDTD & 15 & & \\
\hline \multirow{2}{*}{$\begin{array}{l}\text { Saberes peda- } \\
\text { gógicos para } \\
\text { educ a c ão } \\
\text { superior }\end{array}$} & CAPES & 44 & \multirow[t]{2}{*}{13} & \multirow[t]{2}{*}{0} \\
\hline & BDTD & 459 & & \\
\hline \multirow{2}{*}{$\begin{array}{l}\text { D o c ê n c i a } \\
\text { universitária }\end{array}$} & CAPES & 65 & \multirow[t]{2}{*}{9} & \multirow[t]{2}{*}{5} \\
\hline & BDTD & 217 & & \\
\hline \multirow{2}{*}{$\begin{array}{l}\text { Form aça o } \\
\text { inicial }\end{array}$} & CAPES & 1660 & \multirow[t]{2}{*}{2} & \multirow[t]{2}{*}{0} \\
\hline & BDTD & 2222 & & \\
\hline \multirow{2}{*}{$\begin{array}{l}\text { Form a ça a o } \\
\text { continuada }\end{array}$} & CAPES & 1660 & \multirow[t]{2}{*}{37} & \multirow[t]{2}{*}{0} \\
\hline & BDTD & 2223 & & \\
\hline Total & $\begin{array}{r}- \\
\end{array}$ & 8615 & 100 & 23 \\
\hline
\end{tabular}

Fonte | Elaborada pelas autoras

Embora as fontes de pesquisa tenham apresentado grande quantidade de trabalhos relacionados aos descritores definidos, a maioria das pesquisas identificadas discute assuntos gerais que envolvem a formação docente. Por isso, a partir da leitura inicial dos resumos, foram selecionados vinte e três (23) trabalhos para a elaboração do Estado da Questão, sendo quatorze (14) 
A formação pedagógica de docentes bacharéis na educação superior: construindo o Estado da Questão

dissertações e nove (9) teses. $\bigcirc$ Quadro 1 apresenta informações básicas sobre os trabalhos selecionados.

Quadro 1

Dados básicos dos trabalhos selecionados para o diálogo com ○ objeto de investigação

\begin{tabular}{|c|c|c|c|c|}
\hline Autor & Título & Tipo & Curso & Instituição/ano \\
\hline $\begin{array}{l}\text { A N D R A E, } \\
\text { Telga Persivo } \\
\text { Pontes de. }\end{array}$ & $\begin{array}{l}\text { O professor universitário, sem } \\
\text { formação pedagógica, a ori- } \\
\text { gem e a construção de sua } \\
\text { práxis docente: que raciona- } \\
\text { lidade? Que caminhos? }\end{array}$ & Tese & $\begin{array}{l}\text { Douto rado } \\
\text { em Educação } \\
\text { Brasileira }\end{array}$ & $\begin{array}{l}\text { Un iversidade } \\
\text { Federal do Ceará/ } \\
2006\end{array}$ \\
\hline $\begin{array}{l}\text { B A S Í LI I O, } \\
\text { Vanessa Hidd. }\end{array}$ & $\begin{array}{l}\text { A prática pedagógica no } \\
\text { ensino superior: o desafio de } \\
\text { tornar-se professor. }\end{array}$ & Dissertação & $\begin{array}{l}\text { Mestrado em } \\
\text { Educação }\end{array}$ & $\begin{array}{l}\text { Un iversidade } \\
\text { Federal do Piauí/ } \\
2010\end{array}$ \\
\hline $\begin{array}{l}\text { BERNARDINO } \\
\text { JÚ } U \text { I OR. } \\
\text { Roberto. }\end{array}$ & $\begin{array}{l}\text { Docência universitária: o ci- } \\
\text { rurgião dentista no curso de } \\
\text { odontologia. }\end{array}$ & Tese & $\begin{array}{l}\text { Doutorado em } \\
\text { Educação }\end{array}$ & $\begin{array}{l}\text { Universidade } \\
\text { Federal de } \\
\text { Uberlândia/ } 2011\end{array}$ \\
\hline $\begin{array}{l}\text { CAMARGO, } \\
\text { Mar c e I a } \\
\text { Pedroso de. }\end{array}$ & $\begin{array}{l}\text { Docência universitária e } \\
\text { formação pedagógica: um } \\
\text { olhar para a Universidade } \\
\text { Estadual de Londrina. }\end{array}$ & Dissertação & $\begin{array}{l}\text { Mestrado em } \\
\text { Educação }\end{array}$ & $\begin{array}{l}\text { Universidade } \\
\text { Estadual de } \\
\text { Londrina/ } 2012\end{array}$ \\
\hline $\begin{array}{l}\text { C A M P E LO, } \\
\text { Arandi Maciel. }\end{array}$ & $\begin{array}{l}\text { Os saberes docentes constru- } \\
\text { ídos pelos professores e as } \\
\text { práticas de ensino no curso } \\
\text { superior de Administração da } \\
\text { FCAP/UPE. }\end{array}$ & Tese & $\begin{array}{l}\text { Doutorado em } \\
\text { Educação }\end{array}$ & $\begin{array}{l}\text { Universidade } \\
\text { Federal de } \\
\text { Pernambuco/2011 }\end{array}$ \\
\hline $\begin{array}{l}\text { CÓsSIO, Maria } \\
\text { de Fátima. }\end{array}$ & $\begin{array}{l}\text { Políticas institucionais de for- } \\
\text { mação pedagógica e seus } \\
\text { efeitos na configuração da } \\
\text { docência e na qualidade uni- } \\
\text { versitária : um estudo sobre } \\
\text { as IES comunitárias do RS. }\end{array}$ & Tese & $\begin{array}{l}\text { Doutorado em } \\
\text { Educação }\end{array}$ & $\begin{array}{l}\text { Universidade } \\
\text { Federal do Rio } \\
\text { Grande do Sul/ } \\
2008\end{array}$ \\
\hline $\begin{array}{l}\text { D A N T A S, } \\
\text { Cecília Maria } \\
\text { Macedo. }\end{array}$ & $\begin{array}{l}\text { O desenvolvimento da do- } \\
\text { cência nas engenharias: } \\
\text { um estudo na Universidade } \\
\text { Federal de Campina Grande } \\
\text { (UFCG). }\end{array}$ & Dissertação & $\begin{array}{l}\text { Mestrado em } \\
\text { Educação }\end{array}$ & $\begin{array}{l}\text { Universidade } \\
\text { Federal do Rio } \\
\text { Grande do Norte/ } \\
2011\end{array}$ \\
\hline
\end{tabular}




\begin{tabular}{|c|c|c|c|c|}
\hline Autor & Título & Tipo & Curso & Instituição/ano \\
\hline $\begin{array}{l}\text { FORESTI, Roque } \\
\text { Antonio. }\end{array}$ & $\begin{array}{l}\text { Médico: ser ou não ser pro- } \\
\text { fessor? Implicações para a } \\
\text { conduta médica e a profissio- } \\
\text { nalidade docente. }\end{array}$ & Dissertação & $\begin{array}{l}\text { Mestrado em } \\
\text { Educação }\end{array}$ & $\begin{array}{l}\text { Universidade do } \\
\text { Vale do ltajaí/2012 }\end{array}$ \\
\hline $\begin{array}{l}\text { FURTADO, José } \\
\text { Augusto Paz } \\
\text { Ximenes. }\end{array}$ & $\begin{array}{l}\text { A construção de saberes } \\
\text { docentes no cotidiano das } \\
\text { práticas de ensinar: um estu- } \\
\text { do focalizando o docente do } \\
\text { ensino jurídico. }\end{array}$ & Dissertação & $\begin{array}{ll}\text { Mestrado } & \text { em } \\
\text { Ciências } & d a \\
\text { Educação } & \end{array}$ & $\begin{array}{l}\text { Universidade } \\
\text { Federal do } \\
\text { Piaú/2007 }\end{array}$ \\
\hline $\begin{array}{l}\text { F R A N C O, } \\
\text { Maria Estela Dal } \\
\text { Pai. }\end{array}$ & $\begin{array}{l}\text { Docência no ensino superior: } \\
\text { revelando saberes dos profes- } \\
\text { sores da área da saúde da } \\
\text { UNICRUZ/RS. }\end{array}$ & Tese & $\begin{array}{l}\text { Doutorado em } \\
\text { Educação }\end{array}$ & $\begin{array}{ll}\text { Universidade } \\
\text { Federal do Rio } \\
\text { Grande } & \text { do } \\
\text { Su/2009 } & \end{array}$ \\
\hline $\begin{array}{l}\text { GONZÁLEZ, } \\
\text { Alberto Durán. }\end{array}$ & $\begin{array}{l}\text { Ser docente na área da } \\
\text { saúde: uma abordagem } \\
\text { à luz da fenomenologia } \\
\text { heideggeriana. } \\
\end{array}$ & Tese & Doutorado & $\begin{array}{l}\text { Universidade } \\
\text { Estadual de } \\
\text { Londrina/2012 }\end{array}$ \\
\hline $\begin{array}{l}\text { L A C E R D A, } \\
\text { Cecília Rosa. }\end{array}$ & $\begin{array}{l}\text { A experiência do exercício } \\
\text { da profissão e o saber ensi- } \\
\text { nar: estudo com professores } \\
\text { dos cursos de bacharelado. }\end{array}$ & Tese & $\begin{array}{l}\text { Doutorado } \\
\text { em Educação } \\
\text { Brasileira }\end{array}$ & $\begin{array}{l}\text { Universidade } \\
\text { Federal do } \\
\text { Ceará/2011 }\end{array}$ \\
\hline $\begin{array}{l}\text { MEDRA D O, } \\
\text { Glaucia Cristina } \\
\text { da Rocha. }\end{array}$ & $\begin{array}{l}\text { Tornar-se professor de } \\
\text { Administração: um estudo } \\
\text { sobre o papel da afetividade } \\
\text { na trajetória profissional. }\end{array}$ & Dissertação & $\begin{array}{l}\text { Mestrado em } \\
\text { Educaçã o: } \\
\text { Psicologia da } \\
\text { Educação }\end{array}$ & $\begin{array}{l}\text { Pontific i a } \\
\text { Universidade } \\
\text { Católica de São } \\
\text { Paulo/2012 }\end{array}$ \\
\hline $\begin{array}{l}M|S S| O, \\
\text { Lourdes. }\end{array}$ & $\begin{array}{l}\text { O entrelaçar dos fios na cons- } \\
\text { trução da identidade docente } \\
\text { dos professores do Curso de } \\
\text { Enfermagem da UEMS. }\end{array}$ & Tese & $\begin{array}{l}\text { Doutorado em } \\
\text { Educação }\end{array}$ & $\begin{array}{l}\text { Universidade } \\
\text { Estadual de } \\
\text { Mato Grosso do } \\
\text { Sul/2007 }\end{array}$ \\
\hline $\begin{array}{l}\text { MOR A E S, } \\
\text { Eliane Gouveia } \\
\text { de. }\end{array}$ & $\begin{array}{l}\text { Docência universitária: o pro- } \\
\text { fessor fisioterapeuta no curso } \\
\text { de fisioterapia. }\end{array}$ & Dissertação & $\begin{array}{l}\text { Mestrado em } \\
\text { Educação }\end{array}$ & $\begin{array}{l}\text { Universidade } \\
\text { Federal de } \\
\text { Uberlândia/2008 }\end{array}$ \\
\hline $\begin{array}{l}\text { NUNES, Zigmar } \\
\text { Borges. }\end{array}$ & $\begin{array}{l}\text { Ensino superior: per- } \\
\text { cepção do docente de } \\
\text { enfermagem quanto à forma- } \\
\text { ção pedagógica. }\end{array}$ & Dissertação & $\begin{array}{l}\text { Mestrado em } \\
\text { Ciências }\end{array}$ & $\begin{array}{l}\text { Universidade de } \\
\text { São Paulo/2011 }\end{array}$ \\
\hline $\begin{array}{l}\text { P I V E T T A, } \\
\text { Hedion e ida } \\
\text { Maria Foletto. }\end{array}$ & $\begin{array}{l}\text { Concepções de formação } \\
\text { e docência dos professores } \\
\text { do Curso de Fisioterapia } \\
\text { do Centro Universitário } \\
\text { Franciscano. }\end{array}$ & Dissertaçãa & $\begin{array}{l}\text { Mestrado em } \\
\text { Educação }\end{array}$ & $\begin{array}{l}\text { Mestrado } \\
\text { Educação }\end{array}$ \\
\hline
\end{tabular}


A formação pedagógica de docentes bacharéis na educação superior: construindo o Estado da Questão

\begin{tabular}{|c|c|c|c|c|}
\hline Autor & Título & Tipo & Curso & Instituição/ano \\
\hline $\begin{array}{l}\text { RODRIGUES, } \\
\text { Algaides de } \\
\text { Marco. }\end{array}$ & $\begin{array}{l}\text { Tornar-se professor de } \\
\text { Psicologia: encontros com o } \\
\text { outro. }\end{array}$ & Tese & $\begin{array}{l}\text { Doutorado em } \\
\text { Educação }\end{array}$ & $\begin{array}{l}\text { Universidade } \\
\text { Federal } \quad d e \\
\text { Pelotas/2011 }\end{array}$ \\
\hline $\begin{array}{l}\text { ROLINDO, Joicy } \\
\text { Mara Rezende. }\end{array}$ & $\begin{array}{l}\text { A formação didático-pedagó- } \\
\text { gica dos bacharéis docentes: } \\
\text { uma análise a partir das re- } \\
\text { presentações dos professores } \\
\text { do curso de engenharia agrí- } \\
\text { cola da UEG. }\end{array}$ & Dissertação & $\begin{array}{l}\text { Mestrado em } \\
\text { Educação }\end{array}$ & $\begin{array}{l}\text { Universidade } \\
\text { Católicard de } \\
\text { Goiás/2008 }\end{array}$ \\
\hline $\begin{array}{l}\text { S A N T O S , } \\
\text { Patrícia Peixoto } \\
\text { dos. }\end{array}$ & $\begin{array}{l}\text { Socialização profissional } \\
\text { dos professores engenheiros } \\
\text { ingressantes na educação } \\
\text { superior. }\end{array}$ & Dissertação & $\begin{array}{l}\text { Mestrado em } \\
\text { Educação }\end{array}$ & $\begin{array}{l}\text { Universidade } \\
\text { Federal de } \\
\text { Uberlândia/ } \\
2013\end{array}$ \\
\hline $\begin{array}{l}\text { SILVA, Dayse } \\
\text { Souza da. }\end{array}$ & $\begin{array}{l}\text { Formação de professores de } \\
\text { educação superior de cursos } \\
\text { de graduação na área de } \\
\text { saúde. }\end{array}$ & Dissertação & $\begin{array}{l}\text { Mestrado em } \\
\text { Educação }\end{array}$ & $\begin{array}{l}\text { Universidade } \\
\text { Católica de } \\
\text { Brasília/2008 }\end{array}$ \\
\hline $\begin{array}{l}\text { SILVA, Stephane } \\
\text { da. }\end{array}$ & $\begin{array}{l}\text { Constituição de identidades } \\
\text { docentes de professores de } \\
\text { um curso jurídico: a recontex- } \\
\text { tualização curricular. }\end{array}$ & Dissertação & $\begin{array}{l}\text { Mestrado em } \\
\text { Educação }\end{array}$ & $\begin{array}{l}\text { Universidade } \\
\text { Federal de } \\
\text { Pelotas/2011 }\end{array}$ \\
\hline $\begin{array}{l}\mathrm{Y} \cap \cup E \\
\text { Alessandra } \\
\text { Tiemi. }\end{array}$ & $\begin{array}{l}\text { A capacitação do profissio- } \\
\text { nal de fisioterapia para a } \\
\text { docência no ensino superior. }\end{array}$ & Dissertação & $\begin{array}{l}\text { Mestrado em } \\
\text { Educação }\end{array}$ & $\begin{array}{l}\text { Universidade } \\
\text { do } \quad O \text { este } \\
\text { Paulista/2011 }\end{array}$ \\
\hline
\end{tabular}

Fonte | Elaborado pelas autoras

No segundo momento, a pesquisa buscou identificar artigos científicos publicados em periódicos e anais de eventos científicos que abordassem a temática em questão. Foi realizado um levantamento a partir do banco de periódicos Capes e dos anais de dois (2) eventos: Reunião Anual da Associação Nacional de Pós-Graduação e Pesquisa em Educação (ANPEd), nos anos de 201 1, 2012 e 2013, e Encontro Inter-Regional Norte, Nordeste e CentroOeste de Formação Docente para a Educação Superior (ENFORSUP), no mesmo período. Essa fase da pesquisa foi desenvolvida em maio de 2014. O desenvolvimento da pesquisa a partir de publicações em periódicos qualificados pela Capes na área de avaliação Educação ocorreu da seguinte forma: inicialmente, fizemos uma busca em periódicos Qualis A 1, A2 e B 1 e B2 visto que esses estratos representam os periódicos mais bem avaliados junto aos Programas de Pós-Graduação em Educação no país. Não havendo 
encontrado artigos relacionados à nossa investigação, ampliamos a consulta aos periódicos Qualis B3, B4 e B5.

Outra fonte de dados utilizada foi o levantamento de publicação de artigos em anais de eventos. Nesse momento, escolhemos os trabalhos da Associação Nacional de Pós-Graduação e Pesquisa em Educação (ANPED), por considerarmos a importância desse encontro para as discussões nacionais acerca da educação superior. $\bigcirc$ segundo evento, Encontro Inter-Regional Norte, Nordeste e Centro-Oeste de Formação Docente para a Educação Superior (ENFORSUP), foi selecionado por abordar temas específicos da formação docente para esse nível de educação, representando um panorama das pesquisas nas regiões Norte, Nordeste e Centro-Oeste do País. Consideramos que essa etapa da pesquisa foi fundamental para complementar o mapeamento dos estudos acerca da formação e atuação do docente bacharel no âmbito nacional, permitindo uma melhor análise sobre os enfoques e as reflexões desenvolvidas acerca da nossa proposta investigativa.

A consulta realizada nas revistas científicas procedeu-se por meio de busca avançada por assunto de artigos publicados nos últimos dez (10) anos, considerando os seguintes critérios de seleção: ser publicado em periódicos qualificados pela Capes, tendo como área de avaliação Educação, abordar especificamente o docente bacharel e ser escrito em língua portuguesa. Os descritores definidos para a busca foram: docente bacharel; formação do docente bacharel; saberes pedagógicos de bacharéis; saberes pedagógicos para educação superior; docência universitária; formação inicial; formação continuada; formação de professores da educação superior; formação de professores; formação do docente universitário; docente universitário e pedagogia universitária, conforme Tabela 2. 
A formação pedagógica de docentes bacharéis na educação superior: construindo o Estado da Questão

\section{Tabela 2}

Síntese quantitativa dos artigos publicados em periódicos Qualis/Capes

\begin{tabular}{l|c|c}
\multicolumn{1}{c|}{ Descritores } & Total de registros & Total selecionado \\
\hline Docente bacharel & 30 & 0 \\
\hline Formação do docente bacharel & 18 & 0 \\
\hline Saberes pedagógicos de bacharéis & 0 & 0 \\
\hline Saberes pedagógicos para educação superior & 0 & 0 \\
\hline Docência universitária & 28 & 0 \\
\hline Formação inicial & 15 & 0 \\
\hline Formação continuada & 26 & 1 \\
\hline Formação de professores da educação superior & 0 & 0 \\
\hline Formação de professores & 0 & 0 \\
\hline Formação do docente universitário & 237 & 6 \\
\hline Docente universitário & 329 & 1 \\
\hline Pedagogia universitária & 985 & 0 \\
\hline Total & 1668 & 8
\end{tabular}

Fonte | Elaborada pelas autoras

A definição dos coletores foi sendo feita à medida que identificamos a necessidade de ampliar as possibilidades de buscas; visto que, embora a pesquisa apresentasse quantidade significativa de resultados, os títulos dos artigos abordavam temas gerais da docência e não a docência por parte do profissional bacharel. Outro aspecto a ser destacado é que a maioria dos trabalhos registrados estava escrito em língua estrangeira. Foram selecionados oito (8) artigos publicados em periódicos científicos. $\bigcirc$ Quadro 2 apresenta os principais dados desses artigos. 


\section{Quadro 2}

\section{Principais informações dos artigos publicados em revistas científicas selecionados}

\begin{tabular}{|c|c|c|c|}
\hline Autor(es) & Título & Revista/ano & $\begin{array}{c}\text { Estrato } \\
\text { Qualis }\end{array}$ \\
\hline BATISTA, Nildo Alves. & $\begin{array}{l}\text { Desenvolvimento docente na área } \\
\text { da saúde: uma análise. }\end{array}$ & $\begin{array}{l}\text { Trabalho, Educação e } \\
\text { Saúde/2005. }\end{array}$ & B2 \\
\hline $\begin{array}{l}\text { FERREIRA JÚNIOR, } \\
\text { Marcos Antonio. }\end{array}$ & $\begin{array}{l}\text { Os reflexos da formação ini- } \\
\text { cial na atuação dos professores } \\
\text { enfermeiros. }\end{array}$ & $\begin{array}{l}\text { Revista Brasileira de } \\
\text { Enfermagem/2008. }\end{array}$ & B3 \\
\hline $\begin{array}{l}\text { BACKES, Vânia Marli } \\
\text { Schubert; MOYÁ, Jose } \\
\text { Luis Medina; PRADO, } \\
\text { Marta Lenise do. }\end{array}$ & $\begin{array}{l}\text { Processo de construção do conhe- } \\
\text { cimento pedagógico do docente } \\
\text { universitário de enfermagem. }\end{array}$ & $\begin{array}{l}\text { Revista Latino- } \\
\text { A m e r c a } \mathrm{n} \text {. } \\
\text { Enfermagem/2011 }\end{array}$ & B3 \\
\hline $\begin{array}{l}\text { MIRANDA, Gilberto } \\
\text { José; CASA NOVA, } \\
\text { Silvia Pereira de Castro; } \\
\text { CORNACCHIONE } \\
\text { JÚNIOR, Edgard Bruno. }\end{array}$ & $\begin{array}{l}\text { Os saberes dos professores-referên- } \\
\text { cia no ensino de Contabilidade. }\end{array}$ & $\begin{array}{l}\text { Revista Contabilidade e } \\
\text { Finanaças/ } 2012\end{array}$ & B3 \\
\hline $\begin{array}{l}\text { BACKES, Dirce Stein; } \\
\text { MARINHO, Mara; } \\
\text { COSTENARO, Regina } \\
\text { Santini; NUNES, } \\
\text { Simone; RUPOLO, Irani. }\end{array}$ & $\begin{array}{l}\text { Repensando o ser enfermeiro } \\
\text { docente na perspectiva do pensa- } \\
\text { mento complexo. }\end{array}$ & $\begin{array}{l}\text { Revista Brasileira de } \\
\text { Enfermagem/2010 }\end{array}$ & B3 \\
\hline $\begin{array}{l}\text { A B E N S R }, \\
\text { Silvia Itzcovici; } \\
\text { TAMOSAUSKAS, } \\
\text { Marcia Rodrigues } \\
\text { Garcia. }\end{array}$ & $\begin{array}{l}\text { Tecnologia da Informação e } \\
\text { Comunicação na formação docen- } \\
\text { te em saúde: relato de experiência. }\end{array}$ & $\begin{array}{ll}\text { Revista } & \text { Brasileira } \\
\text { de } & \text { Educação } \\
\text { Médica/2011. }\end{array}$ & B3 \\
\hline $\begin{array}{l}\text { BALTAZAR, Mariângela } \\
\text { Monteiro de Melo; } \\
\text { MOYSÉS, Samuel Jorge; } \\
\text { BASTOS, Carmen Célia } \\
\text { Barradas Correia. }\end{array}$ & $\begin{array}{l}\text { Profissão, docente de odontologia: } \\
\text { o desafio da pós-graduação na for- } \\
\text { mação de professores. }\end{array}$ & $\begin{array}{l}\text { Trabalho, Educação e } \\
\text { Saúde/2010 }\end{array}$ & B3 \\
\hline SLOMSKI, Vilma Geni. & $\begin{array}{l}\text { Saberes e competências do profes- } \\
\text { sor universitário: contribuições para } \\
\text { o estudo da prática pedagógica do } \\
\text { professor de Ciências Contábeis do } \\
\text { Brasil. }\end{array}$ & $\begin{array}{|lr|}\text { Revistar } & d e \\
\text { Contabilidaderãas/2007 } & e \\
\text { Organizaçes }\end{array}$ & B4 \\
\hline
\end{tabular}

Fonte | Elaborado pelas autoras 
A formação pedagógica de docentes bacharéis na educação superior: construindo o Estado da Questão

Para a seleção desses artigos, foi feita, inicialmente, a leitura dos temas buscando o enfoque na docência do profissional graduado na modalidade bacharelado. Em seguida, procedeu-se à leitura dos resumos dos trabalhos selecionados.

Conforme podemos observar no Quadro 2, os oito (8) artigos selecionados estão distribuídos da seguinte forma: um (1) artigo publicado em revista Qualis B2, 6 (seis) publicados em revistas B3 e um (1) publicado em revista B4. Ressaltamos que não identificamos nenhum artigo publicado em revista qualificada como A 1, A2, B 1 e B5; esse fato sinaliza que ainda há um longo caminho a ser percorrido, seja com pesquisas sobre a temática, seja (sobretudo) em relação a publicações.

Em sequência, verificamos as publicações nos anais de dois eventos: Reuniões da ANPEd (201 1, 2012, 2013), Grupo de Trabalho (GT08): Formação de Professores e ENFORSUP (201 1, 201 2,2013), Grupos de trabaIhos: Desenvolvimento profissional docente para atuação com/na diversidade na educação superior e profissional-tecnológica: saberes pedagógicos, identidade profissional, currículo e formação pedagógica. $\bigcirc$ Quadro 3 apresenta as principais informações dos artigos selecionados nos anais do ENFORSUP.

\section{Quadro 3}

Principais informações dos artigos publicados nos anais do ENFORSUP no período de 2011 a 2013

\begin{tabular}{|l|l|c|}
\hline \multicolumn{1}{|c|}{ Autorles) } & \multicolumn{1}{|c|}{ Título } & Ano \\
\hline $\begin{array}{l}\text { CARVALHO, Genyvana Criscya } \\
\text { Garcia; BRITO, Antonia Edna. }\end{array}$ & $\begin{array}{l}\text { Docência no ensino superior: o pro- } \\
\text { fessor bacharel e as aprendizagens } \\
\text { docentes. }\end{array}$ & 2013 \\
\hline $\begin{array}{l}\text { DIAS, Ana Maria lorio; BARROS, } \\
\text { Conceição de Maria Pinheiro; SILVA, } \\
\text { Joelma Soares da; SILVA, Chirley Lima } \\
\text { da. }\end{array}$ & $\begin{array}{l}\text { A formação dos docentes em } \\
\text { de educação superior do Brasil. }\end{array}$ & 2013 \\
\hline JORDÃO, Larissa; CLARO, Marcel. & $\begin{array}{l}\text { A educação no século XXl e a formação } \\
\text { do professor reflexivo na arquitetura. }\end{array}$ & 2012 \\
\hline $\begin{array}{l}\text { SILVA, Naísa Afonso da.; BARAÚNA, } \\
\text { Malusá Silvana. }\end{array}$ & $\begin{array}{l}\text { A prática do docente universitário } \\
\text { no curso de Direito e a formação do } \\
\text { aluno. }\end{array}$ & 2012 \\
\hline
\end{tabular}




\begin{tabular}{|c|c|c|}
\hline Autor(es) & Título & Ano \\
\hline $\begin{array}{l}\text { CARVALHO, Renata Innecco Bittencourt } \\
\text { de. }\end{array}$ & $\begin{array}{l}\text { A prática pedagógica do bacharel } \\
\text { professor da área de Comunicação } \\
\text { Social. }\end{array}$ & 2012 \\
\hline $\begin{array}{l}\text { SILVA, Wellington dos Reis; KATO, } \\
\text { Marly Nunes de Castro; ANDRADE, } \\
\text { Luiza Vitória Vital de. }\end{array}$ & $\begin{array}{l}\text { Desenvolvimento Profissional Docente: } \\
\text { socialização e identidade dos profes- } \\
\text { sores da área de Ciências Biomédicas } \\
\text { da UFU. }\end{array}$ & 2012 \\
\hline $\begin{array}{l}\text { LIMA, Maria da Glória Soares } \\
\text { Barbosa. }\end{array}$ & $\begin{array}{l}\text { O bacharel na docência superior: re- } \\
\text { tratos de pesquisa do PPGED. }\end{array}$ & 2012 \\
\hline $\begin{array}{l}\text { BERNINI, Giovanna Márcia Cristina; } \\
\text { SANTOS, Patricia Peixoto dos; DIAS, } \\
\text { Caroline. }\end{array}$ & $\begin{array}{l}\text { professor de ciências exatas no } \\
\text { contexto universitário: dilemas e } \\
\text { perspectivas. }\end{array}$ & 2012 \\
\hline BORGES, Camila Cunha de Araújo. & $\begin{array}{l}\text { Didática e prática pedagógica do pro- } \\
\text { fessor de Administração. }\end{array}$ & 2012 \\
\hline $\begin{array}{l}\text { SAMPAIO, Arlene Luttigards Oliveira } \\
\text { Vaz; LEPORACE, Viviane Reis. }\end{array}$ & $\begin{array}{l}\text { Formação Docente: Análise pedagógi- } \\
\text { ca sobre desafios do docente-bacharel } \\
\text { na educação profissional e ensino su- } \\
\text { perior - IF Baiano Campus Santa Inês } \\
\text { - BA. }\end{array}$ & 2012 \\
\hline $\begin{array}{l}\text { SOUZA, Ana Cláudia de; DIAS, } \\
\text { Elisângela Teixeira G. }\end{array}$ & $\begin{array}{l}\text { Formação pedagógica na prática do- } \\
\text { cente no ensino superior: percepção } \\
\text { de professores da área de saúde. }\end{array}$ & 2012 \\
\hline $\begin{array}{l}\text { FREITAS, Emílio Campelo; LEITINHO, } \\
\text { Meirecele Calíope. }\end{array}$ & $\begin{array}{l}\text { Docência universitária em cursos de } \\
\text { Engenharia: um estudo exploratório. }\end{array}$ & 2011 \\
\hline $\begin{array}{l}\text { MOURA, Adriana Borges Ferro; LIMA, } \\
\text { Maria da Glória Soares Barbosa. }\end{array}$ & $\begin{array}{l}\text { Docência no ensino superior: um } \\
\text { olhar sobre a prática pedagógica do } \\
\text { bacharel. }\end{array}$ & 2011 \\
\hline $\begin{array}{l}\text { LIMA, Maria da Glória Soares } \\
\text { Barbosa; COSTA, Ivna Maria Mello. }\end{array}$ & $\begin{array}{l}\text { Percorrendo o conhecimento e a for- } \\
\text { mação pedagógica do fisioterapeuta } \\
\text { professor. }\end{array}$ & 2011 \\
\hline $\begin{array}{l}\text { GUIMARÃES, Isac Pimentel; FERREIRA, } \\
\text { Rosilda Arruda. }\end{array}$ & $\begin{array}{l}\text { Pesquisa-ação aplicada às Ciências } \\
\text { Contábeis: uma possibilidade teórico- } \\
\text {-metodológica para a formação de } \\
\text { professores. }\end{array}$ & 2011 \\
\hline EUGÊNIO, Benedito G. & $\begin{array}{l}\text { De bacharel a professor: processos de } \\
\text { aprendizagem da docência no ensino } \\
\text { superior. }\end{array}$ & 2011 \\
\hline
\end{tabular}

Fonte | Elaborado pelas autoras 
Por meio da leitura dos resumos nos Grupos de Trabalho que abordam o tema, procuramos artigos que discutissem, especificamente, a formação ou aspectos da atuação do docente bacharel.

A pesquisa nos anais do ANPEd apresentou sessenta e quatro (64) registros de artigos; no entanto, nenhum trabalho foi selecionado, por não abordar questões acerca do docente bacharel. Nos anais do ENFORSUP, entre oitenta (80) trabalhos registrados, foram selecionados dezesseis (16).

A interpretação das informações obtidas nesta investigação teve como técnica a análise de conteúdo, buscando identificar convergências e diferenças entre as abordagens feitas nas pesquisas. Conforme Bardin (2009, p. 27), a análise de conteúdo "[... observa com interesse as tentativas que se fazem no campo alargado da análise de comunicações: lexicometria, enunciação linguística, análise de conversação, documentação e base de dados, etc". Como resultados dessa análise, apresentamos, a seguir, o mapeamento e a interpretação da produção científica acerca da temática formação pedagógica e atuação do docente bacharel.

\section{Afinal, o que dizem as dissertações e teses sobre formação pedagógica e atuação do professor bacharel?}

As pesquisas em dissertações e teses localizadas nos bancos de dados revelaram uma crescente preocupação com o tema, conforme consta na Tabela 3.

\section{Tabela 3}

Evolução das pesquisas em dissertações e teses sobre o docente bacharel

\begin{tabular}{l|c|c|c|c|c|c|c|c|c}
$\begin{array}{l}\text { Tipo } \\
\text { publicação }\end{array}$ & 2005 & 2006 & 2007 & 2008 & 2009 & 2010 & 2011 & 2012 & 2013 \\
\hline Dissertações & 0 & 1 & 1 & 3 & 0 & 1 & 4 & 3 & 1 \\
\hline Teses & 0 & 1 & 1 & 1 & 1 & 0 & 4 & 1 & 0 \\
\hline Subtotal & 0 & 2 & 2 & 4 & 1 & 1 & 8 & 4 & 1 \\
\hline Total & \multicolumn{9}{|c|}{23}
\end{tabular}

Fonte | Dados da pesquisa 
Percebemos o aumento de interesse pela temática no decorrer das décadas, destacando-se o desenvolvimento de investigações em 2011 com maior quantidade de defesas. Esse aumento aponta para a relevância do assunto no âmbito acadêmico; significa, também, que ainda há muito a ser discutido, visto que a continuidade de debate, acerca dessa temática, pode sinalizar que ainda não foi possível chegar à consolidação das questões que envolvem os problemas que se colocam em relação à formação pedagógica e atuação do profissional bacharel que ingressa na carreira docente.

Com relação aos enfoques das investigações, observamos uma tendência de pesquisas acerca de áreas específicas, representadas pela formação inicial do docente bacharel. Sob esse aspecto, destacamos, em maior quantidade, o foco na atuação de professores bacharéis graduados nas áreas: Odontologia, Engenharia, Medicina, Direito, Saúde, Administração, Enfermagem, Fisioterapia e Psicologia. A Tabela 4 apresenta uma síntese dos assuntos abordados nos títulos dos trabalhos.

\section{Tabela 4}

Principais assuntos focalizados nos temas das investigações analisadas

\begin{tabular}{l|c}
\multicolumn{1}{c|}{ Assuntos } & Quantidades \\
\hline Formação pedagógica & 7 \\
\hline Prática docente & 1 \\
\hline Saberes docentes & 3 \\
\hline Políticas de formação docente & 1 \\
\hline Desenvolvimento docente & 1 \\
\hline Ser docente e identidade & 4 \\
\hline Experiência profissional e docência & 1 \\
\hline Docência universitária & 2 \\
\hline Tornar-se professor & 2 \\
\hline Socialização profissional dos professores & 1 \\
\hline & 23
\end{tabular}

Fonte | Dados da pesquisa

Percebemos que os assuntos de maior interesse destacados nos temas dos trabalhos estão relacionados à formação pedagógica dos professores 
A formação pedagógica de docentes bacharéis na educação superior: construindo o Estado da Questão

bacharéis. Essa preocupação pode ser explicada pela existência de críticas relacionadas à pouca presença ou valorização de conhecimentos específicos nos saberes docentes, por parte de bacharéis que se tornam professores universitários.

Esse fato leva ao destaque de outro assunto apresentado nas pesquisas: os saberes docentes. Observamos a tendência dos pesquisadores em estudarem a construção desses saberes, como aspecto relevante para a atuação desses professores. Ressaltamos, ainda, as investigações que focalizaram o ser docente e a constituição de sua identidade. Essa tendência, provavelmente ocorre em virtude de inúmeros questionamentos, como: por que o bacharel escolhe a docência? Como o bacharel de torna professor? As pesquisas denotam a necessidade de encontrar respostas para essas inquietações.

Outros assuntos focalizados nos temas dos trabalhos são: prática docente, políticas de formação docente, desenvolvimento docente, experiência profissional e docência, docência universitária, tornar-se professor e socialização profissional dos professores. Esses temas aparecem em menor percentual, no total de dissertações e teses selecionadas. Não obstante, confirmam que as investigações estão sendo desenvolvidas a partir da identificação das peculiari-

58 dades das áreas de formação inicial dos bacharéis, mudando-se, dessa forma, - lócus de realização das pesquisas - numa interessante abordagem que parte do geral para o(s) específico(s), desvelando necessidades idiossincráticas que somente a práxis identifica. Em seguida, analisamos os problemas e objetivos das pesquisas, buscando um delineamento dos aspectos da formação docente abordados nas investigações. Podemos observar essas abordagens na Tabela 5 .

\section{Tabela 5}

\section{Direcionamento dos problemas e objetivos das pesquisas}

\begin{tabular}{l|c}
\multicolumn{1}{c|}{ Direcionamento dos problemas e objetivos } & Quantidade \\
\hline Formação docente & 6 \\
\hline Formação pedagógica & 2 \\
\hline Perspectiva institucional da docência universitária e formação pedagógica & 1 \\
\hline Saberes pedagógicos & 2 \\
\hline $\begin{array}{l}\text { Formação pedagógica como política institucional e profissionalidade } \\
\text { docente }\end{array}$ & 1 \\
\hline
\end{tabular}


Conceição de Maria Pinheiro Barros | Ana Maria lorio Dias

\begin{tabular}{l|c}
\hline \multicolumn{1}{c|}{ Direcionamento dos problemas e objetivos } & Quantidade \\
\hline Práticas pedagógicas e atividade docente & 3 \\
\hline Tornar-se professor e constituição docente & 5 \\
\hline $\begin{array}{l}\text { Experiências profissionais específicas e elaboração de competências para } \\
\text { a docência }\end{array}$ & 1 \\
\hline Trajetória profissional e afetividade & 1 \\
\hline Socialização do docente bacharel & 1 \\
\hline \multicolumn{1}{c|}{ Total } & 23
\end{tabular}

Fonte | Dados da pesquisa

Os dados revelaram que os problemas e os objetivos das investigações possuem, como principal direcionamento, o conhecimento da formação e da prática pedagógica dos professores graduados em cursos de bacharelado. Outra preocupação, que se destaca nas dissertações e teses analisadas, é a construção de saberes pedagógicos. Ressaltam-se, ainda, abordagens que buscam investigar aspectos relacionados às experiências profissionais e suas relação com a docência, trajetórias da profissão docente e afetividade e socialidade do professor bacharel.

\section{E o que revelam os artigos publicados em periódicos e anais de eventos científicos?}

Analisamos os principais aspectos dos artigos científicos brasileiros publicados em periódicos e eventos selecionados para o Estado da Questão. Destaca-se a evolução das publicações no período de 2005 a 2013 , sobretudo nos seguintes aspectos: enfoque dos temas, problemas, objetivos e metodologia. Na Tabela 6, observamos a evolução das publicações acerca da temática. 
A formação pedagógica de docentes bacharéis na educação superior: construindo o Estado da Questão

\section{Tabela 6}

Evolução das publicações de artigos em periódicos e eventos no período de 2005 a 2013

\begin{tabular}{l|c|c|c|c|c|c|c|c|c}
$\begin{array}{l}\text { Tipo de } \\
\text { publicação }\end{array}$ & 2005 & 2006 & 2007 & 2008 & 2009 & 2010 & 2011 & 2012 & 2013 \\
\hline Revista científica & 1 & 0 & 1 & 1 & 0 & 2 & 2 & 1 & 0 \\
\hline Evento & 0 & 0 & 0 & 0 & 0 & 0 & 5 & 9 & 2 \\
\hline Subtotal & 1 & 0 & 1 & 1 & 0 & 2 & 7 & 10 & 2 \\
\hline Total & \multicolumn{9}{|c|}{24}
\end{tabular}

Fonte | Dados da pesquisa

As publicações dos artigos em periódicos e eventos científicos emergem de forma crescente, tendo maior quantidade de publicações em 2012. Constatamos a existência de poucos artigos publicados em periódicos científicos acerca do docente bacharel, o que remete à necessidade de uma maior visibilidade das pesquisas que têm sido desenvolvidas sobre essa temática, especialmente nos programas de pós-graduação. Com relação aos assuntos identificados, nos títulos dos artigos selecionados, apresentamos a Tabela 7 a seguir.

Tabela 7

Assuntos apresentados nos temas de artigos publicados em periódicos e eventos

\begin{tabular}{l|c}
\multicolumn{1}{c|}{ Assunto } & Quantidade \\
\hline Professor bacharel e aprendizagem docente & 2 \\
\hline Docentes secretários executivos & 1 \\
\hline Professor de Arquitetura & 1 \\
\hline Docente de Direito & 1 \\
\hline Docente de Comunicação Social & 1 \\
\hline Professor de Administração & 1 \\
\hline Educação Tecnológica & 1 \\
\hline Professor de Engenharia & 1 \\
\hline Saberes e práticas pedagógicas & 4 \\
\hline Professor fisioterapeuta & 1 \\
\hline Professor de Ciências Contábeis & 4 \\
\hline Professor da área de saúde & 6 \\
\hline
\end{tabular}

Fonte | Dados da pesquisa 
Os assuntos que permeiam as pesquisas publicadas em periódicos e eventos, com foco no docente bacharel, apontam para uma preocupação com a atuação desses professores nas áreas de saúde e Contabilidade. Observamos, ainda, uma quantidade significativa de pesquisas que abordam a temática saberes e práticas desses professores e aprendizagem docente.

Assim como ocorre nas pesquisas de pós-graduação, os artigos científicos apresentam uma tendência a estudar áreas específicas de profissionais bacharéis que atuam como professores na educação superior, tais como: Secretariado Executivo, Arquitetura, Direito, Comunicação Social, Administração, Engenharia e Fisioterapia.

Em seguida, analisamos os enfoques dos objetivos e dos problemas apresentados nos artigos, conforme Tabela 8.

\section{Tabela 8}

Enfoque dos objetivos e problemas dos artigos publicados em periódicos e eventos científicos

\begin{tabular}{l|c}
\multicolumn{1}{c|}{ Assunto } & Quantidade \\
\hline Constituição docente & 4 \\
\hline Formação docente & 6 \\
\hline Prática pedagógica & 9 \\
\hline Formação continuada & 1 \\
\hline Desenvolvimento profissional docente & 1 \\
\hline Formação inicial & 1 \\
\hline Saberes docentes & 1 \\
\hline Tecnologia da informação e Comunicação & 24
\end{tabular}

Fonte | Dados da pesquisa

Principal enfoque dos objetivos e problemas dos trabalhos refere-se à prática pedagógica, seguida de formação docente e constituição docente. Os artigos discutem, também, temas que envolvem formação continuada, o desenvolvimento docente, os reflexos da formação inicial na prática pedagógica, saberes e conhecimentos, entre outros. 


\section{Em síntese, as contribuições das pesquisas para as discussões acerca da formação do docente bacharel}

Observamos que as pesquisas analisadas preocupam-se com os aspectos motivadores que impulsionam o bacharel a tornar-se docente. Nesse sentido, Silva (2008) conclui que o principal fator motivador, para a inserção do bacharel na docência, é o "gosto pelo ensino". Complementando essa ideia, Medrado (2012) salienta que os bacharéis (no caso de sua pesquisa, os administradores) atuam na docência por motivo afetivo e pelo gosto e prazer em ministrar aulas. Na percepção de González (2012, p. 6), "[... ] o estímulo para a docência por parte dos participantes de sua pesquisa existia a partir da oportunidade de ingresso na educação, de status e da necessidade de um segundo emprego". Conforme Silva (2008), muitos profissionais sinalizaram o desejo de atuar exclusivamente na docência; mas, por outro lado, alguns consideram a docência como uma atividade que complementa a sua profissão.

No tocante à constituição docente, destacamos o estudo de Pivetta (2006, p. 5), que, ao desenvolver pesquisa com professores fisioterapeutas, concluiu que as "[...] concepções de formação e docência [... ] estão entrelaça-

62 das e vêm sendo construídas ao longo da trajetória docente". No entendimento de Missio (2007), essa constituição ocorre em diversos contextos e momentos históricos da trajetória do professor, sendo construída ao longo de toda a vida pessoal e profissional. Em outra linha de pensamento, Silva (2011) pondera que os profissionais que não possuem formação pedagógica, encontram na docência a sua realização profissional e consideram salutar o convívio entre docentes. Acrescenta que os fatores que contribuem para a constituição de sua identidade são as atividades do cotidiano acadêmico relacionadas à categoria recontextualização curricular.

Sob esse aspecto, ressaltamos, ainda, a pesquisa realizada por Furtado (2007) com docentes do ensino jurídico. Em sua percepção, esses profissionais tornam-se docentes na educação superior por meio da vivência cotidiana das práticas de ensinar. A investigação de Basílio (2010, p. 9), com foco na atuação de advogados docentes, denotou que eles "[...] ressignificam suas concepções de docência ao longo do seu percurso no magistério superior". 
Rolindo (2008) argumenta que a formação pedagógica, no curso de engenharia, também é desenvolvida por meio da prática e experiência a partir de erros e acertos. Santos (2013) corrobora essa reflexão, ao afirmar que os engenheiros se constituem docentes a partir dos processos de erros e acertos, em busca de um trabalho mais adequado. Nessa mesma linha de pensamento, Dantas (201 1) discute a percepção da prática de ensino dos docentes-engenheiros dos cursos de Engenharia Civil, Elétrica e de Materiais da Universidade Federal de Campina Grande (UFCG), afirmando que os professores possuem uma tendência a experimentar uma pedagogia da prática no cotidiano, acreditando que a docência se aprende com a prática, mas reconhecem que essa forma não é suficiente para o desenvolvimento profissional.

Com relação à constituição de docentes da área de saúde, González (2012, p. 6) concluiu que "[...] os docentes buscaram referências na impessoalidade da cotidianidade do mundo da educação para subsidiar a construção do ser-docente". Para Rodrigues (201 1), o psicólogo constitui-se professor a partir dos encontros vivenciados em seus fazeres e nos espaços de compartilhamento com a comunidade acadêmica. Em outra linha de pensamento, defende-se que a constituição do docente para a educação superior ocorre por meio da prática profissional. Essa ideia é defendida por Andrade (2006), ao afirmar que as experiências profissionais são fundamentais para a prática docente. Entretanto, conhecimentos isolados não são suficientes para constituir um bom professor, pois esse se faz na conjugação de vários saberes, construídos por meio da práxis da profissão docente.

Nesse sentido, Lacerda (201 1) ressalta que os conhecimentos construídos, no exercício da profissão, podem ser articulados aos saberes docentes na educação superior. Nessa mesma perspectiva, Nunes (2011) defende que a maioria dos professores inseridos na docência na educação superior possui, como referência, a vivência da prática profissional. A nosso ver, embora importante, a experiência profissional não é suficiente para a atuação do bacharel como professor. Assim, concordamos com a ideia de Andrade (2006), ao considerar que somente a experiência não é capaz de tornar esse profissional apto para enfrentar os desafios do professorado e que uma formação direcionada para a construção de saberes pedagógicos é necessária.

Diante do exposto, constatamos que a análise das pesquisas evidenciou problemas relacionados à ausência de formação pedagógica. Sob esse aspecto, destacamos as investigações de Moraes (2008), Bernardino Júnior 
A formação pedagógica de docentes bacharéis na educação superior: construindo o Estado da Questão

(201 1) e Ynove (2011). Esses estudos reconhecem e salientam a necessidade de conhecimentos pedagógicos para preencher as lacunas existentes na formação de bacharéis que atuam como professores na educação superior. Essas considerações são complementadas por estudos que destacam como ocorre a construção de saberes pedagógicos por esses profissionais, visto que o curso de bacharelado não forma para a docência. Entre esses estudos, destacamos os de Andrade (2006) e Furtado (2007), que apontam inquietações acerca de quais são e como são construídos os saberes pelo bacharel que se insere na carreira acadêmica.

\section{Considerações finais: o que nos ensina o Estado da Questão?}

Em busca das contribuições dos estudos sobre o docente bacharel, podemos perceber que as pesquisas têm sido desenvolvidas em cursos específicos de formação como Administração, Contabilidade, Direito, Enfermagem, entre outros. Embora as investigações sejam desenvolvidas em campos de atuação diferentes, os enfoques permeiam a preocupação com temas semeIhantes. Entre os assuntos estudados, ressaltam-se a motivação para a docência, a constituição docente, ausência e a necessidade de formação pedagógica, a construção de saberes pedagógicos, as formações inicial e continuada. Assim, reafirmamos a importância das pesquisas realizadas para constituir o Estado da Questão; estas se tornaram relevantes na medida em que ressaltaram os estudos desenvolvidos sobre a temática, bem como as lacunas percebidas nas investigações analisadas e que podem ser preenchidas por meio de outra(s) investigação(ões).

Sobre a motivação para a docência, as pesquisas revelaram três aspectos principais: "gosto/amor pelo ensino", uma forma de "complemento à sua profissão" e a docência acontecendo "por acaso". Diante dessa realidade, indagamos: qual é o papel das instituições, para que haja uma maior motivação desses professores, em relação à profissionalização docente? $\bigcirc$ que as Instituições de Educação Superior, que recebem os professores bacharéis, têm feito para que haja formação pedagógica e maior motivação no exercício da docência?

No que se referem à constituição docente, os estudos analisados denotam que a docência é estabelecida, para os bacharéis, principalmente por 
meio da prática de ensino. Consideramos fundamental, nas instituições que acolhem esse profissional, a existência de ações com o intuito de oferecer espaços de reflexão e formação pedagógica aos docentes.

Outro aspecto a ser ressaltado é a construção de saberes pedagógicos dos docentes bacharéis. As investigações apontam que o professor bacharel utiliza, principalmente, os saberes da experiência e os saberes específicos de sua área de formação inicial. Consideramos que tais saberes, embora relevantes, não são suficientes para a atuação docente na educação superior.

fato de que a docência configura uma possível área de atuação para o bacharel, cuja formação inicial não aborda os saberes pedagógicos, salienta-se a carência de se abordar esse aspecto desde a graduação do bacharel. Essa ideia é reforçada por Ferreira Júnior (2008), ao considerar que é preciso contemplar os aspectos pedagógicos na formação inicial do profissional. Entendemos que a formação continuada não pode assumir toda a responsabilidade pela formação desse professor. Da mesma forma, a pós-graduação também deveria ter a docência para a educação superior como preocupação - e transformar a "prepação" (estabelecida no art. 66, da LDB, Lei 9.394/96, de 20 de dezembro de 1996) em efetiva formação docente para esse nível de ensino.

Também não podemos deixar "[...] à mercê de cada professor, individualmente, a determinação e a busca" por formação e desenvolvimento profissionais docentes (DIAS, 2010, p. 76). É preciso um foco maior, tanto para a formação inicial, quanto para a formação continuada, visando encontrar possíveis soluções para a construção de saberes pedagógicos dos professores bacharéis. Nessa linha de pensamento, emerge o seguinte questionamento: quais são as possibilidades de se focalizar os saberes pedagógicos na formação inicial do bacharel?

Salientamos, assim, a necessidade de aprofundamento das discussões sobre a formação continuada por meio da institucionalização de ações formativas na IES, de forma sistemática, voltadas especificamente para esse profissional, com base na construção de conhecimentos docentes e vinculadas ao seu desenvolvimento profissional docente. $\bigcirc$ diálogo com as investigações analisadas evidenciou que a consolidação da ideia de que o docente bacharel necessita de conhecimentos pedagógicos é consenso entre os pesquisadores. 
A formação pedagógica de docentes bacharéis na educação superior: construindo o Estado da Questão

que se faz necessário aprofundar é a busca por possíveis soluções para essa problemática.

\section{Nota}

1 Manteremos os termos "universitário" e "universidade" sempre que se referirem à citação de autores (ou quando se referir à expressão utilizada pelo autor). Preferimos os termos "educação superior" e "Instituições de Educação Superior" por considerarmos que, dessa forma, abrangemos, também, as instituições e os docentes que atuam em faculdades e ou centros universitários.

\section{Referências}

ANDRADE, Telga Persivo Pontes de. O professor universitário, sem formação pedagógica, a origem e a construção de sua práxis docente: que racionalidade? Que caminhos? 2006. 129f. Tese (Doutorado em Educação Brasileira) - Programa de Pós-Graduação em Educação, Universidade Federal do Ceará, Fortaleza, 2006. Disponível em: http://www. repositorio.ufc.br/handle/riufc/3291. Acesso em: 6 abr. 2014.

66 ABENSUR, Silvia Itzcovici; TAMOSAUSKAS, Marcia Rodrigues Garcia. Tecnologia da informação e comunicação na formação docente em saúde: Relato de experiência. Revista Brasileira de Educação Médica, Rio de Janeiro, v. 35, n. 1, p. 102-107, jan./mar. 2011. Disponível em: http://www.scielo.br/pdf/rbem/v35n 1/al4v35nl.pdf. Acesso em: 14 out. 2015.

BACKES, Dirce Stein; MARINHO, Mara; COSTENARO, Regina Santini; NUNES, Simone; RUPOLO, Irani. Repensando o ser enfermeiro docente na perspectiva do pensamento complexo. Revista Brasileira de Enfermagem, Brasília, v. 63, n. 3, p. 421-426, maio/jun. 2010. Disponível em: http://www.scielo.br/pdf/reben/v63n3/a12v63n3.pdf. Acesso em: 14 out. 2015.

BACKESI, Vânia Marli Schubert; MOYÁll, Jose Luis Medina; PRADO, Marta Lenise do. Processo de construção do conhecimento pedagógico do docente universitário de enfermagem. Revista Latino-Americana de Enfermagem, Ribeirão Preto, v. 19, n. 2, p. 421-428, mar./abr. 2011 . Disponível em: http://www.scielo.br/scielo.php?pid=S0104- $11692011000200026 \&$ script=sci_arttext\&tlng=pt. Acesso em: 14 out.2015.

BALTAZAR, Mariângela Monteiro de Melo; MOYSES, Samuel Jorge; BASTOS, Carmen Célia Barradas Correia. Profissão, docente de odontologia: o desafio da pós-graduação na formação de professores. Trabalho, Educação e Saúde, Rio de Janeiro, v. 8, n. 2, p. 
285-303, jul./out. 2010. Disponível em: http://www.scielo.br/pdf/tes/v8n2/a07v8n2. pdf. Acesso em: 14 out. 2015.

BARDIN, Laurence. Análise de conteúdo. Lisboa: Edições 70/ LDA, 2009.

BASílIO, Vanessa Hidd. A prática pedagógica no ensino superior: o desafio de tornar-se professor. 201 0. 124f. Dissertação (Mestrado em Educação) - Programa de Pós-Graduação em Educação, Universidade Federal do Piauí, Teresina, 2010. Disponível em: http://www. ufpi.br/subsiteFiles/ppged/arquivos/files/dissertacao/2010/Vanessa_Hidd.pdf. Acesso em: 12 out. 2014.

BATISTA, Nildo Alves. Desenvolvimento docente na área da saúde: uma análise. Trabalho, Educação e Saúde, Rio de Janeiro, v. 3, n. 2, p. 283-294, set. 2005. Disponível em: http://www.scielo.br/pdf/tes/v3n2/03.pdf. Acesso em: 14 out. 2015.

BERNARDINO JÚNIOR, Roberto. Docência universitária: o cirurgião dentista no curso de odontologia. 2011 . 236f. Tese (Doutorado em Educação) - Programa de pós-graduação em Educação, Universidade Federal de Uberlândia, Uberlândia, 2011. Disponível em: http://capesdw.capes.gov.br/?login-url-success=/capesdw/. Acesso em: 30 mar. 2014.

BERNINI, Giovanna Márcia Cristina; SANTOS, Patricia Peixoło dos; DIAS, Caroline. O professor de ciências exatas no contexto universitário: dilemas e perspectivas. In: ENCONTRO INTER-REGIONAL NORTE, NORDESTE E CENTRO-OESTE DE FORMAÇÃO DOCENTE PARA A EDUCAÇÃO SUPERIOR, 4., 2012, Uberlândia. Anais... Urbelândia: Universidade Federal de Uberlândia, 2012. 1 CD-ROM.

BORGES, Camila Cunha de Araújo. Didática e prática pedagógica do professor de Administração. In: ENCONTRO INTER-REGIONAL NORTE, NORDESTE E CENTRO-OESTE DE FORMAÇÃO DOCENTE PARA A EDUCAÇÃO SUPERIOR, 4., 2012, Uberlândia. Anais... Urbelândia: Universidade Federal de Uberlândia, 2012. 1 CD-ROM.

BRASIL. Lei de Diretrizes e Bases da Educação Nacional. Lei n 9.394, de 20 de dezembro de 1996. Estabelece as Diretrizes e Bases da Educação Nacional. Disponível em: hitp:// portal.mec.gov.br/arquivos/pdf/ldb. pdf. Acesso em: 6 fev. 2015.

CAMARGO, Marcela Pedroso de. Docência universitária e formação pedagógica: um olhar para a Universidade Estadual de Londrina. 2012. 128f. Dissertação Mestrado em Educação) - Programa de Pós-Graduação em Educação, Universidade Estadual de Londrina, Londrina, 2012. Disponível em: http://www.uel.br/pos/mestredu/images/stories/downloads/dissertacoes/2012/2012__CAMARGO_Marcela_Pedroso.pdf . Acesso em: 14 out. 2015. 
A formação pedagógica de docentes bacharéis na educação superior: construindo o Estado da Questão

CAMPELO, Arandi Maciel. Os saberes docentes construídos pelos professores e as práticas de ensino no curso superior de administração da FCAP/UPE. 2011. 291f. Tese (Doutorado em Educação) - Universidade Federal de Pernambuco, Recife, 2011 . Disponível em: http://www.arandi.adm.br/pdf/Arandi.tese.pdf. Acesso em: 25 mar. 2014.

CARVAlHO, Genyvana Criscya Garcia; BRITO, Antonia Edna. Docência no ensino superior: o professor bacharel e as aprendizagens docentes. In: ENCONTRO INTER-REGIONAL NORTE NORDESTE E CENTRO-OESTE DE FORMAÇÃO DOCENTE PARA A EDUCAÇÃO SUPERIOR, 5., 2013, Terezina. Anais... Terezina: Universidade Federal do Piauí, 2013.1 CD-ROM.

CARVALHO, Renata Innecco Bittencourt de. A prática pedagógica do bacharel professor da área de Comunicação Social. In: ENCONTRO INTER-REGIONAL NORTE NORDESTE E CENTRO-OESTE E FORMAÇÃO DOCENTE PARA A EDUCAÇÃO SUPERIOR, 4., 2012, Uberlândia. Anais... Uberlândia: Universidade Federal de Uberlândia, 2012. 1 CD-ROM.

CÓSSIO, Maria de Fátima. Políticas institucionais de formação pedagógica e seus efeitos na configuração da docência e na qualidade universitária: um estudo sobre as IES comunitárias do RS. 2008. 226f. Tese (Doutorado em Educação) - Universidade Federal do Rio Grande do Sul. Rio Grande do Sul, 2008. Disponível em: http://www.lume.ufrgs.br/ handle/10183/13275. Acesso em: 25 abr. 2014.

CUNHA, Maria Isabel da. Diferentes Olhares Sobre as Práticas Pedagógicas no Ensino Superior: a docência e sua formação. Educação, Porto Alegre, n. 3, v. 27, p. 525-536, set./dez. 2004. Disponível em: http://revistaseletronicas.pucrs.br/fo/ojs/index.php/ faced/article/view/397/294. Acesso em: 24 fev. 2015.

DANTAS, Cecília Maria Macedo. O desenvolvimento da docência nas engenharias: um estudo na Universidade Federal de Campina Grande (UFCG). 2011. 122f. Dissertação (Mestrado em Educação) - Programa de Pós-Graduação em Educação, Universidade Federal do Rio Grande do Norte, Natal, 201 1. Disponível em: http://repositorio.ufrn.br:8080/ jspui/bitstream/1/10200/1/CeciliaMMD_DISSERT.pdf. Acesso em: 2 mar. 2014.

DIAS, Ana Maria lorio. Leitura e (autolformação: caminhos percorridos por docentes na Educação Superior. In: VEIGA, Ilma Passos Alencastro; VIANA, Cleide Maria Quevedo Quixadá (Org.). Docentes para a educação superior: processos formativos. Campinas: Papirus, 2010.

DIAS, Ana Maria lorio; BARROS, Conceição de Maria Pinheiro; SILVA, Joelma Soares da; SILVA, Chirley Lima da. A formação dos docentes em Secretariado Executivo das Instituições de Educação Superior do Brasil. In: ENCONTRO INTER-REGIONAL NORTE, NORDESTE E 
CENTRO-OESTE DE FORMAÇÃO DOCENTE PARA A EDUCAÇÃO SUPERIOR, 5., 2013, Teresina. Anais... Teresina: Universidade Federal do Piauí, 2013. 1 CD-ROM.

DURKHEIM, Émile. Educação e sociologia. 11. ed. Tradução Nuno Garcia Lopes. Lisboa: Edições 70, 2007.

ECO, Umberto. Como se faz uma tese. 21 . ed. Tradução Gilson César Cardoso de Souza. São Paulo: Perspectiva, 2008.

EUGÊNIO, Benedito Gonçalves. De bacharel a professor: processos de aprendizagem da docência no ensino superior. In: ENCONTRO INTER-REGIONAL NORTE, NORDESTE E CENTRO-OESTE DE FORMAÇÃO DOCENTE PARA A EDUCAÇÃO SUPERIOR, 3., 2011 , Salvador. Anais... Salvador: Fundação Visconde de Cairu, 201 1. 1 CD-ROM.

FERREIRA JÚNIOR, Marcos Antonio. Os reflexos da formação inicial na atuação dos professores enfermeiros. Revista Brasileira de Enfermagem, Brasilia, v. 61, n. 6, p. 866-871, nov./dez. 2008. Disponível em: http://www.scielo.br/pdf/reben/v6lnb/al2v6ln6. pdf. Acesso em: 14 out. 2015.

FORESTI, Roque Antonio. Médico: ser ou não ser professor? Implicações para a conduta médica e a profissionalidade docente. 2012. 94f. Dissertação (Mestrado em Educação) Universidade do Vale do Itajaí, Itajaí, Santa Catarina. Disponível em: http://wwwb.univali. br/tede/tde_busca/arquivo. php?codArquivo=1092. Acesso em: 2 maio 2014.

FREIRE, Paulo. Educação e mudança. 12. ed. Rio de Janeiro: Paz e Terra, 2009.

FREITAS, Emílio Campelo; LEITINHO, Meirecele Calíope. Docência universitária em cursos de Engenharia: um estudo exploratório. In: ENCONTRO INTER-REGIONAL NORTE, NORDESTE E CENTRO-OESTE DE FORMAÇÃO DOCENTE PARA A EDUCAÇÃO SUPERIOR, 3., 201 1, Salvador. Anais... Salvador: Fundação Visconde de Cairu, 2011. 1CD-ROM.

FRANCO, Maria Estela Dal Pai. Docência no ensino superior: revelando saberes dos professores da área da saúde da UNICRUZ/RS. 2009. 207f. Tese (Doutorado em Educação) - Universidade Federal do Rio Grande do Sul, Porto Alegre, 2009. Disponível em: hitp:// www.lume.ufrgs. br/bitstream/handle/10183/24164/000745080. pdf? sequence $=1$. Acesso em: 20 abr. 2014.

FURTADO, José Augusto Paz Ximenes. A construção de saberes docentes no cotidiano das práticas de ensinar: um estudo focalizando o docente do ensino jurídico. 2007. $162 f$. Dissertação (Mestrado em Ciências da Educação) - Programa de Pós-Graduação em Educação, Universidade Federal do Piauí, Teresina, 2007. Disponível em: http:// www.ufpi. 
A formação pedagógica de docentes bacharéis na educação superior: construindo o Estado da Questão

br/subsiteFiles/ppged/arquivos/files/dissertacao/2008/construca_saberes.pdf. Acesso em: 4 abr. 2014.

GIL, Antônio Carlos. Didática do ensino superior. São Paulo: Atlas, 2009.

GONZÁLEZ, Alberto Durán. Ser docente na área da saúde: uma abordagem à luz da fenomenologia heideggeriana. Londrina, Paraná. 2012. $115 f$. Tese (Doutorado em Saúde Coletiva) - Programa de Pós-Graduação em Saúde Coletiva, Universidade Estadual de Londrina. Londrina, 2012. Disponível em: http://www.uel.br/pos/saudecoletiva/Doutorado/teses/ tese/1.pdf. Acesso em: 4 abr. 2014.

GUIMARÃES, Isac Pimentel; FERREIRA, Rosilda Arruda. Pesquisa-ação aplicada às ciências contábeis: uma possibilidade teórico-metodológica para a formação de professores. In: ENCONTRO INTER-REGIONAL NORTE, NORDESTE E CENTRO-OESTE DE FORMAÇÃO DOCENTE PARA A EDUCAÇÃO SUPERIOR, 3., 2011 , Salvador. Anais... Salvador: Fundação Visconde de Cairu, 201 1. 1 CD-ROM.

JORDÃO, Larissa Caroline Silva; CLARO, Marcel Alessandro. A Educação no século XXI e a formação do Professor reflexivo na Arquitetura. In: ENCONTRO INTER-REGIONAL NORTE, NORDESTE E CENTRO-OESTE DE FORMAÇÃO DOCENTE PARA A EDUCAÇÃO SUPERIOR, 4., 2012, Urbelândia. Anais... Uberlândia: Universidade Federal de Urbelândia, 2012.1

70 CD-ROM.

LACERDA, Cecília Rosa. A experiência do exercício da profissão e o saber ensinar: estudo com professores dos cursos de bacharelado. 2011 . 248f. Tese (Doutorado em Educação Brasileira) - Programa de Pós-Graduação em Educação, Universidade Federal do Ceará, Fortaleza, 2011 . Disponível em: http://www.si3.ufc.br/sigaa/public/programa/noticias_ desc.jsf?noticia=10290670\&id=10056. Acesso em: 3 abr. 2014.

LIMA, Maria da Glória Soares Barbosa; COSTA, Ivna Maria Mello. Percorrendo o conhecimento e a formação pedagógica do fisioterapeuta professor. In: ENCONTRO INTERREGIONAL NORTE, NORDESTE E CENTRO-OESTE DE FORMAÇÃO DOCENTE PARA A EDUCAÇÃO SUPERIOR, 3., 2011 , Salvador. Anais... Salvador: Fundação Visconde de Cairu, 2011.1 CD-ROM.

LIMA, Maria da Glória Soares Barbosa. O bacharel na docência superior: retratos de pesquisa do PPGED. In: ENCONTRO INTER-REGIONAL NORTE, NORDESTE E CENTROOESTE DE FORMAÇÃO DOCENTE PARA A EDUCAÇÃO SUPERIOR, 4., 2012, Uberlândia.

Anais... Uberlândia: Universidade Federal de Urbelândia, 2012. 1 CD-ROM.

MARCONI, Marina de Andrade; LAKATOS, Eva Maria. Metodologia do trabalho científico. 5. ed. São Paulo: Atlas, 2001. 
MASETTO, Marcos Tarciso. Professor Universitário: um profissional da educação na atividade docente. In: MASETTO, Marcos (Org.). Docência na universidade. São Paulo: Papirus, 1998.

MEDRADO, Glaucia Cristina da Rocha. Tornar-se professor de administração: um estudo sobre o papel da afetividade na trajetória profissional. 2012. 158f. Dissertação (Mestrado em Educação) - Programa de Pós-Graduação em Educação, Pontifícia Universidade Católica de São Paulo, 2012. Disponível em: http://www.sapientia.pucsp.br/tde_busca/processaPesquisa. php?listaDetalhes\%5B\%5D=12385\&processar=Processar. Acesso em: 2 maio 2014.

MIRANDA, Gilberto José; CASA NOVA, Silvia Pereira de Castro; CORNACCHIONE JÚNIOR, Edgard Bruno. Os saberes dos professores-referência no ensino de contabilidade.

Revista de Contabilidade \& Finanças, São Paulo, v. 23, n. 59, p. 142-153, maio/ago. 2012. Disponível em: http://www.scielo.br/pdf/rct/v23n59/v23n59a06.pdf. Acesso em: 14 out. 2015.

MISSIO, Lourdes. O entrelaçar dos fios na construção da identidade docente dos professores do curso de enfermagem da UEMS. 2007, 282f. Tese (Doutorado em Educação) - Universidade Estadual de Mato Grosso do Sul, Paranaíba, 2007. Disponível em: http:// www. bibliotecadigital.unicamp.br/document/? code=vtls000423305. Acesso em: 30 mar. 2014.

MORAES, Eliane Gouveia de. Docência universitária: o professor fisioterapeuta no curso de fisioterapia. 2008. 66f. Dissertação (Mestrado em Educação) - Programa de Pós-Graduação em Educação, Universidade Federal de Uberlândia. Uberlândia, 2008. Disponível em: http://busca.ibict.br/SearchBDTD/search.do. Acesso em: 7 abr. 2014.

MOURA, Adriana Borges Ferro; LIMA, Maria da Glória Soares Barbosa. Docência no ensino superior: um olhar sobre a prática pedagógica do bacharel. In: ENCONTRO INTERREGIONAL NORTE, NORDESTE E CENTRO-OESTE DE FORMAÇÃO DOCENTE PARA A EDUCAÇÃO SUPERIOR, 3, 201 1, Salvador. Anais... Salvador: Fundação Visconde de Cairu, 2011. 1 CD-ROM.

NÓBREGA-THERRIEN, Sílvia Maria; THERRIEN, Jacques. $\bigcirc$ estado da questão: aportes teórico-metodológicos e relatos de sua produção em trabalhos científicos. In: FARIAS, Isabel Maria Sabino de; NUNES, João Batista Carvalho; NÓBREGA-TERRIEN, Silvia Maria (Org.).

Pesquisa científica para iniciantes: caminhando no labirinto. Fortaleza: EdUECE, 2010.

NUNES, Zigmar Borges. Ensino superior: percepção do docente de enfermagem quanto à formação pedagógica. 2011. 122f. Dissertação (Mestrado em Ciências) - Programa 
A formação pedagógica de docentes bacharéis na educação superior: construindo o Estado da Questão

de Pós-Graduação em Enfermagem Fundamental, Universidade de São Paulo, Ribeirão Preto, 2011 . Disponível em: file:///C:/Users/concei\%C3\%A7\%C3\%A3o/Downloads/ ZigmarBorgesNunes.pdf. Acesso em: 14 abr. 2014.

PIVETTA, Hedioneida Maria Foletto. Concepções de formação e docência dos professores do curso de fisioterapia do Centro Universitário Franciscano. 2006. $134 f$. Dissertação (Mestrado em Educação) - Universidade Federal de Santa Maria, Santa Maria, 2006. Disponível em: http://cascavel.cpd.ufsm.br/tede/tde_busca/arquivo. php? codArquivo=531. Acesso em: 21 abr. 2014.

RODRIGUES, Algaides de Marco. Tornar-se professor de psicologia: encontros com o outro. 2011 . 125f. Tese (Doutorado em Educação) - Programa de Pós-Graduação em Educação, Universidade Federal de Pelotas, Pelotas, 2011 . Disponível em: taniaporto.dominiotemporario.com/doc/T_2011_algaides.pdf. Acesso em: 15 abr. 2014.

ROLINDO, Joicy Mara Rezende. A formação didático-pedagógica dos bacharéis docentes: uma análise a partir das representações dos professores do curso de engenharia agrícola da UEG. 2008. 16 If. Dissertação (Mestrado em Educação) - Programa de Pós-Graduação em Educação, Universidade Católica de Goiás, Goiânia, 2008. Disponível em: http:// www.openthesis.org/documents/Dos-docentes-uma-partir-das-495283.html. Acesso em: 4 abr. 2014.

SAMPAIO, Arlene Luttigards Oliveira Vaz; LEPORACE, Viviane Reis. In: ENCONTRO INTERREGIONAL NORTE, NORDESTE E CENTRO-OESTE DE FORMAÇÃO DOCENTE PARA A EDUCAÇÃO SUPERIOR, 4., 2012 , Uberlândia. Anais... Uberlândia: Universidade Federal de Uberlândia, 2012. 1 CD-ROM.

SANTOS, Patrícia Peixoto dos. Socialização profissional dos professores engenheiros ingressantes da educação superior. 2013. 11 2f. Dissertação (Mestrado em Educação ) Programa de Pós-Graduação em Educação, Universidade Federal de Uberlância, Uberlândia, 2013. Disponível em: http://repositorio.ufu.br/bitstream/123456789/3449/1/ SocializacaoProfissionalProfessores.pdf. Acesso em: 28 abr. 2014.

SILVA, Dayse Souza da. Formação de professores de educação superior de cursos de graduação na área de saúde. 2008. 100f. Dissertação (Mestrado em Educação) Programa de Pós-Graduação Stricto Sensu em Educação, Universidade Católica de Brasília, Brasília, 2008. Disponível em: http://www.bdtd.ucb.br/tede/tde_busca/arquivo. php? codArquivo=894. Acesso em: 20 abr. 2014.

SILVA, Naísa Afonso da; BARAÚNA, Silvana Balusá. A prática do docente universitário no curso de Direito e a formação do aluno. In: ENCONTRO INTER-REGIONAL NORTE, 
NORDESTE E CENTRO-OESTE DE FORMAÇÃO DOCENTE PARA A EDUCAÇÃO SUPERIOR, 4., 2012 , Uberlândia. Anais... Uberlândia: Universidade Federal de Uberlândia, 2012.1 CD-ROM.

SILVA, Stephane da. Constituição de identidades docentes de professores de um curso jurídico: a recontextualização curricular. 201 1, 105f. Dissertação (Mestrado em Educação) - Universidade Federal de Pelotas, Pelotas, 2011 . Disponível em: http://capesdw.capes. gov.br/?login-url-success=/capesdw/. Acesso em: 20 abr. 2014.

SILVA, Wellington dos Reis; KATO, Marly Nunes de Castro; ANDRADE, Luiza Vitória Vital de. Desenvolvimento Profissional Docente: socialização e identidade dos professores da área de Ciências Biomédicas da UFU. In: ENCONTRO INTER-REGIONAL NORTE, NORDESTE E CENTRO-OESTE DE FORMAÇÃO DOCENTE PARA A EDUCAÇÃO SUPERIOR 4., 2012, Uberlândia. Anais... Uberlândia: Universidade Federal de Uberlândia, 2012. 1 CD-ROM.

SILVEIRA, Clarice Santiago; NÓBREGA-THERRIEN, Sílvia Maria. Estudos sobre pesquisa e formação de professores da Educação Básica: a elaboração do Estado da Questão. Revista Educação em Questão, Natal, v. 41, n. 27, p. 219-243, jul./dez. 2011 . Disponível em: http://www.revistaeduquestao.educ.ufrn.br/pdfs/v4 1n27.pdf Acesso em: 24 fev. 2015.

SLOMSKI, Vilma Geni. Saberes e competências do professor universitário: contribuições para o estudo da prática pedagógica do professor de ciências contábeis do Brasil. RCO - Revista de Contabilidade e Organizações, São Paulo, v. 1, n. 1, p. 87-103, set./ dez. 2007. Disponível em: http://www.rco.usp.br/index.php/rco/article/view/1 1/24. Acesso em: 14 out. 2015.

SOUZA, Ana Cláudia de; DIAS, Elisângela Teixeira Gomes. Formação pedagógica na prática docente no ensino superior: percepção de professores da área de saúde. In: ENCONTRO INTER-REGIONAL NORTE, NORDESTE E CENTRO-OESTE DE FORMAÇÃO DOCENTE PARA A EDUCAÇÃO SUPERIOR 4., 2012 , Uberlândia. Anais... Uberlândia: Universidade Federal de Uberlândia, 2012. 1 CD-ROM.

TARDIF, Maurice. Saberes docentes e formação profissional. Tradução Francisco Pereira. Petrópolis: Vozes, 2002.

VASCONCELOS, Maria Lúcia Marcondes Carvalho. A formação do professor do ensino superior. 2. ed. São Paulo: Pioneira, 2000.

YNOUE, Alessandra Tiemi. A capacitação do profissional de fisioterapia para a docência no ensino superior. 2011 . 87f. Dissertação (Mestrado em Educação) - Programa de PósGraduação em Educação, Universidade do Oeste Paulista, São Paulo, 2011 . Disponível 
em: http://apeclx.unoeste.br/tede/tde_busca/arquivo.php?codArquivo=262. Acesso em: 20 abr. 2014.

Profa. Ms. Conceição de Maria Pinheiro Barros Universidade Federal do Ceará Faculdade de Economia, Administração, Atuárias, Contabilidade e Secretariado Executivo Grupo de Estudos e Pesquisas em Secretariado Executivo | GEPES Email | conceicaompb@ufc.br Profa. Dra. Ana Maria lorio Dias Universidade Federal do Ceará Faculdade de Educação Programa de Pós-Graduação em Educação Grupo de Pesquisa Formação Docente 